\title{
Commentary \\ New insights into the effects on blood pressure of diets low in salt and high in fruits and vegetables and low-fat dairy products
} William M Vollmer, Frank M Sacks* and Laura P Svetkey ${ }^{\dagger}$

Kaiser Permanente Center for Health Research, Portland, Oregon, USA

*Brigham and Women's Hospital, Boston, Massachusetts, USA

${ }^{\dagger}$ Duke University Medical Center, Durham, North Carolina, USA

Correspondence: William M Vollmer, PhD, Senior Investigator, Center for Health Research, 3800 N Interstate Avenue, Portland, OR 97227-1110, USA. Tel: +1 503335 6755; fax: +1 503335 2428; e-mail: william.vollmer@kpchr.org

Received: 12 March 2001

Revisions requested: 14 March 2001

Revisions received: 21 March 2001

Accepted: 30 March 2001

Published: 11 April 2001
Curr Control Trials Cardiovasc Med 2001, 2:71-74

(C) 2001 BioMed Central Ltd

(Print ISSN 1468-6708; Online 1468-6694)

\begin{abstract}
Results from the recent Dietary Approaches to Stop Hypertension (DASH)-Sodium trial provide the latest evidence concerning the effects of dietary patterns and sodium intake on blood pressure. Participants ate either the DASH diet (high in fruits, vegetables and low-fat dairy products, and reduced in saturated and total fat) or a typical US diet. Within each diet arm, participants ate higher, intermediate, and lower sodium levels, each for 30 days. The results indicated lower blood pressure with lower sodium intake for both diet groups. Although some critics would argue otherwise, these findings provide important new evidence for the value of the DASH diet and sodium reduction in controlling blood pressure.
\end{abstract}

Keywords: blood pressure, Dietary Approaches to Stop Hypertension (DASH) trial, hypertension, salt, sodium

\section{Introduction}

High blood pressure, or hypertension, affects almost 50 million people in the USA, and places them at higher risk for cardiovascular disease [1,2]. However, this increased risk from high blood pressure is not limited to those with hypertension. Extensive data show that increased blood pressure is related to increased risk for cardiovascular disease throughout a broad range of both 'normal' and 'hypertensive' blood pressures [3]. Normal blood pressure for an adult is $120 / 80 \mathrm{mmHg}$; high blood pressure, or hypertension, is a systolic blood pressure $\geq 140 \mathrm{mmHg}$ and a diastolic pressure $\geq 90 \mathrm{mmHg}$. Currently recommended dietary strategies for lowering blood pressure include achieving caloric balance in order to avoid overweight, limiting alcohol intake, lowering salt intake, and consuming a diet that is high in fruits, vegetables and lowfat dairy products, and reduced in overall fat content [1]. Of these, the most controversial is the recommendation to reduce sodium intake to no more than $100 \mathrm{mmol} /$ day (2400 mg sodium or $6 \mathrm{~g}$ salt), particularly when directed at the general public. Current US intake, not including discretionary salt added to prepared foods, is appoximately $143 \mathrm{mmol} /$ day sodium, which is equivalent to approximately $8.25 \mathrm{~g}$ salt/day [4].

Current salt recommendations are based on extensive literature that includes animal research, populationbased epidemiologic data, observational studies, and clinical trials [5]. Opponents of these recommendations object most to their use as a broad public health message. They contend that only a small percentage of the population is 'salt sensitive', and that most individuals would not benefit from reducing their salt intake [6]. A few even argue that a reduced salt intake may actually be detrimental to some individuals [7-9], although the studies that support this latter claim have either been based on extremely low levels of sodium intake $(10-20 \mathrm{mmol} /$ day $)$ or have methodologic shortcomings [10-12]. The opposing viewpoints are summarized in two recent editorials $[6,13]$. 
As the discourse has become increasingly polarized, some have argued that the proponents of current salt recommendations have lost their scientific objectivity [14]. At the same time, the major trade association for US salt producers has been an active force in opposing the current guidelines. Several of the scientists who most actively oppose the current guidelines are members of its advisory committee.

The recently concluded DASH-Sodium trial used a rigorously controlled design to examine the impact of sodium reduction on blood pressure in the context of two very different dietary patterns [15]. When the results were first presented at the Annual Meeting of the American Society of Hypertension in May 2000, the US National Heart, Lung, and Blood Institute of the National Institutes of Health, which funded the trial, stated that these results provided the definitive answer to the sodium controversy [16]. The present commentary summarizes the DASHSodium findings, and the reactions to them.

\section{Background}

DASH-Sodium built on the results of the previous Dietary Approaches to Stop Hypertension (DASH) trial [17,18], which showed that a diet (the DASH diet [19]) rich in fruits, vegetables, and low-fat dairy foods and reduced in saturated and total fat, when compared with a more typical American diet, significantly reduced blood pressure. The typical American diet may be characterized as a diet that is high in fat and low in fruits and vegetables. Both studies included adults with above-optimal blood pressure $(120 / 80-139 / 89 \mathrm{mmHg})$ or at the lower range of stage 1 hypertension (140/90-159/95 mmHg). They were conducted as multicenter, controlled feeding trials, in which participants received all their food from the clinical center, and weight, physical activity and alcohol consumption were held constant. The DASH trial also held sodium intake constant at approximately $3000 \mathrm{mg} /$ day dietary sodium, which is slightly below what Americans typically consume. In the DASH trial, $49 \%$ of participants were women, $60 \%$ were African-American, and $29 \%$ had hypertension.

The DASH trial demonstrated that a diet that is rich in fruits, vegetables, and low-fat dairy products could achieve clinically important reductions in blood pressure, as compared with a typical American diet. Those with hypertension had a reduction of $11.4 / 5.5 \mathrm{mmHg}$, and those without hypertension had a reduction of $5.5 / 3.0 \mathrm{mmHg}$. These reductions occurred in the absence of changes in weight or sodium intake, appeared within 2 weeks of being on the diet, and persisted for the 8 weeks of feeding.

\section{The DASH-Sodium trial}

The DASH-Sodium trial examined the impact of sodium reduction on blood pressure within the context of a typical American diet and the DASH diet [20]. The 412 participants were randomly assigned to one of these two diet arms, and within each arm consumed three levels of sodium in random sequence: a 'higher' level of $3300 \mathrm{mg} /$ day, which is comparable to current US intake; an 'intermediate' level of $2400 \mathrm{mg} /$ day, which is equivalent to the upper limit of current US recommendations; and a 'lower' level of $1500 \mathrm{mg} /$ day. Each level of sodium was consumed by each participant for 4 weeks. In the DASHSodium trial, $57 \%$ of participants were women, $57 \%$ were African-Americans, and $41 \%$ had hypertension.

The results of the DASH-Sodium trial showed that reducing dietary sodium lowered blood pressure for the participants on both the typical American diet and the DASH diet [15]. The lower the sodium intake, the lower the blood pressure. Although the reductions were greater for those with hypertension than for those without, they were still significant in the latter group (Table 1). Sodium-related declines were greater for those eating the control diet than the DASH diet, but the lowest blood pressures were observed among those who ate the DASH diet while consuming sodium at the lower level. This combination reduced blood pressure more than either the DASH diet or lower sodium intake alone $(8.9 / 4.5 \mathrm{mmHg}$ below the control diet at the higher sodium level).

\section{The critics say}

Does the DASH-Sodium trial provide the definitive answer to the debate as the National Heart, Lung, and Blood Institute claims? Not so, say critics. They claim it is not reduced sodium that lowers blood pressure, but the DASH diet alone, which contains a 'typical' dietary level of sodium $[21,22]$. It is better, they argue, to focus national nutrition policy on correcting the mineral deficiencies that exist and are worsening in the US diet, without concern for a single nutrient such as salt [6]. They also cite the DASH-Sodium results to support their contention that not all subgroups within the population responded equally, and that for some subgroups the impact of sodium reduction was negligible for those who were already eating the DASH diet.

\section{Responding to the critics}

Although we agree there is merit to the argument that susceptibility to sodium probably varies in the population, this does not mitigate the importance of the recommendations from a public health perspective. Indeed, the same individuals who raised this criticism enthusiastically support the DASH diet despite initial reports that showed marked differences in its effectiveness between those with and without hypertension, and between African-Americans and non-African-Americans; that is, the DASH diet reduced blood pressure more in the participants with hypertension than those without, and more for African-Americans than whites [23]. Moreover, even though the effect of sodium varied across subgroups, the fact remains that lower levels of sodium intake resulted in lower blood pressure for subgroups defined by race, sex, and hypertension 
Table 1

Effect on systolic and diastolic blood pressure of reducing sodium intake from the 'higher' to the 'lower' levels in the DASH-Sodium trial

Effect of diet on blood pressure ( $\mathrm{mmHg}$; mean [95\% confidence interval])

\begin{tabular}{|c|c|c|c|}
\hline \multirow[b]{2}{*}{ Blood pressure } & \multirow[b]{2}{*}{$n$ (control diet/DASH diet) } & \\
\hline & & Participants who ate the control diet & Participants who ate the DASH diet \\
\hline \multicolumn{4}{|l|}{ Systolic } \\
\hline Hypertensive & $83 / 85$ & $-8.3(-10.0$ to -6.6$)$ & $-4.9(-6.6$ to -3.3$)$ \\
\hline Nonhypertensive & $121 / 123$ & $-5.6(-7.0$ to -4.1$)$ & $-1.7(-3.1$ to -0.3$)$ \\
\hline \multicolumn{4}{|l|}{ Diastolic } \\
\hline Hypertensive & $83 / 85$ & $-4.4(-5.5$ to -3.3$)$ & $-2.5(-3.6$ to -1.4$)$ \\
\hline Nonhypertensive & $121 / 123$ & $-2.8(-3.8$ to -1.9$)$ & $-1.1(-2.0$ to -0.1$)$ \\
\hline
\end{tabular}

status, including substantial effects in those without clinical hypertension.

Second, critics have raised the very diversity of the DASH-Sodium population as a limitation of the study, claiming that it represents an especially salt-sensitive subset of the population. Again, it is curious that they choose to overlook this diversity when they cite this same study, and the DASH Trial before it, as evidence of the merit of the DASH diet. The fact is that the DASH-Sodium sample was constructed precisely so that the investigators could make valid statements about the effects of dietary factors in a variety of high-risk and low-risk subgroups. Also, even though the DASH-Sodium results cannot be extrapolated to individuals with 'optimal' (ie below 120/80 $\mathrm{mmHg}$ ) blood pressures, they are directly applicable to the approximately half of the adult US population whose blood pressures are above this level. Furthermore, it is not unreasonable to expect that consumption of the DASH diet at reduced levels of sodium intake may help prevent the development of the higher blood pressures that are associated with increased risk of cardiovascular disease.

Third, although effectively conceding the value of sodium reduction among participants eating the control diet, critics have resorted to the argument that sodium intake is not important because its effect on blood pressure was greatly reduced among those who ate the DASH diet. "Just eat the DASH diet and don't worry about sodium", they say. One could just as easily discount the benefits of the DASH diet because its blood pressure lowering effect was greatly reduced when participants' sodium intake was $50 \mathrm{mmol} /$ day. However, as noted above, critics of the salt findings cite the DASH-Sodium trial as providing reaffirmation of the benefit of the DASH diet. In fact, even though they are not fully additive, the effects of both eating the DASH diet and reducing sodium were greater than the effects of either alone.
Finally, the critics note that DASH-Sodium was a shortterm study, which was conducted under artificial conditions. We believe the controlled feeding design used in the DASH and DASH-Sodium studies was critical in order to establish without question the benefits from these interventions, which are achievable given adequate adherence. The challenge now is to determine ways to help the American public achieve and sustain such adherence. MacGregor et al [24] have shown, assuming that adherence can be maintained, that the blood pressure lowering effects of sodium reduction persist undiminished for as long as a year.

\section{Food industry co-operation}

Ultimately, the US public will find it difficult to make significant reductions in their current sodium intake without the co-operation of the food industry. Approximately $75 \%$ of the sodium that Americans consume comes from salt that has been added to processed foods [25]. Without a change in the foods that can be purchased at the grocery store and in restaurants, the average American consumer will find it difficult to lower his or her salt intake substantially. Consequently, a strong public health campaign is needed to help motivate the food industry to provide more low-sodium alternatives to the foods they produce.

\section{Conclusion}

Proven strategies for reducing blood pressure include increasing physical activity levels, reducing weight, eating the DASH diet, limiting alcohol, and reducing sodium intake. These options are all available to anyone who wishes to lower his or her blood pressure, and adopting them singly or in combination should reduce the risks of stroke and heart and kidney diseases. Having several options available should increase the chance that at least one, if not several, will be attempted. Each of these proven strategies requires long-term commitment and significant lifestyle change to be effective, which may be difficult to 
maintain for the typical person. Nonetheless, health care providers can offer a simple message: eat lots of fruits, vegetables and low-fat dairy products; reduce calories from fat to about 28\%; and reduce consumption of sodium. In addition, co-operation from the food industry in reducing sodium levels in processed foods is crucial for the population to make meaningful reductions in their sodium intake.

\section{Acknowledgement}

The authors gratefully acknowledge the editorial assistance of Ms Martha Swain.

\section{References}

1. Joint National Committee: The sixth report of the Joint National Committee on prevention, detection, evaluation, and treatment of high blood pressure. Arch Intern Med 1997, 157: 2413-2446.

2. National High Blood Pressure Education Program Working Group: National High Blood Pressure Education Program Working Group report on primary prevention of hypertension. Arch Intern Med 1993, 153:186-208.

3. Stamler J, Stamler R, Neaton JD: Blood pressure, systolic and diastolic, and cardiovascular risks. US population data. Arch Intern Med 1993, 153:598-615.

4. Alaimo K, McDowell MA, Briefel RR, Bischof AM, Caughman CR, Loria CM, Johnson CL: Dietary intake of vitamins, minerals, and fiber of persons ages 2 months and over in the United States: Third National Health and Nutrition Examination Survey, Phase 1, 1988-91. Adv Data 1994, 153:1-28.

5. Stamler J: Dietary salt and blood pressure. Ann N Y Acad Sci 1993, 676:122-156.

6. Egan BM, Stepniakowski KT: Adverse effects of short-term, very-low-salt diets in subjects with risk-factor clustering. $\mathrm{Am} \mathrm{J}$ Clin Nutr 1997, 65(suppl):671S-677S.

7. Alderman $\mathrm{MH}$, Cohen $\mathrm{H}$, Madhavan $\mathrm{S}$ : Dietary sodium intake and mortality: the National Health and Nutrition Examination Survey (NHANES I). Lancet 1998, 351:781-785.

8. Alderman $\mathrm{MH}$, Madhavan $\mathrm{S}$, Cohen $\mathrm{H}$, Sealey JE, Laragh JH: Low urinary sodium is associated with greater risk of myocardial infarction among treated hypertensive men. Hypertension 1995, 25:1144-1152.

9. He J, Ogden LG, Vupputuri S, Bazzano LA, Loria C, Whelton PK: Dietary sodium intake and subsequent risk of cardiovascular disease in overweight adults. JAMA 1999, 282:2027-2034.

10. de Wardener HE: Salt reduction and cardiovascular risk: the anatomy of a myth. J Hum Hypertens 1999, 13:1-4.

11. Kumanyika SK, Cutler JA: Dietary sodium reduction: is there cause for concern? J Am Coll Nutr 1997, 16:192-203.

12. McCarron DA: The dietary guideline for sodium: should we shake it up? Yes! Am J Clin Nutr 2000, 71:1013-1019.

13. Kaplan NM: The dietary guideline for sodium: should we shake it up? No. Am J Clin Nutr 2000, 71:1020-1026.

14. Taubes G: The (political) science of salt. Science 1998, 281: 898-897.

15. Sacks FM, Svetkey LP, Vollmer WM, Appel LJ, Bray GA, Harsha D, Obarzanek E, Conlin PR, Miller ER III, Simons-Morton DG, Karanja N, Pao-Hwa L, for the DASH-Sodium Collaborative Research Group: Effects on blood pressure of reduced dietary sodium and the Dietary Approaches to Stop Hypertension (DASH) diet. N Engl J Med 2001, 344:3-10.

16. NHLBI study shows large blood pressure benefit from reduced dietary sodium [press release]. Bethesda: National Institutes of Health, National Heart, Lung, and Blood Institute, May 17 2000. http://www.nhlbi.nih.gov/new/press/may17-00.htm.

17. Sacks FM, Obarzanek E, Windhauser MM, Svetkey LP, Vollmer WM, McCullough M, Karanja N, Pao-Hwa L, Steele P, Proschan MA, Evans MA, Appel LJ, Bray GA, Vogt TM, Moore TJ, for the DASH Investigators: Rationale and design of the Dietary Approaches to Stop Hypertension trial (DASH). A multicenter controlled-feeding study of dietary patterns to lower blood pressure. Ann Epidemiol 1995, 5:108-118.
18. Appel LJ, Moore TJ, Obarzanek E, Vollmer WM, Svetkey LP, Sacks FM, Bray GA, Vogt TM, Cutler JA, Windhauser MM, PaoHwa L, Karanja N, for the DASH Collaborative Research Group: A clinical trial of the effects of dietary patterns on blood pressure. DASH Collaborative Research Group. $N$ Engl J Med 1997, 336:1117-1124.

19. Karanja NM, Obarzanek E, Lin PH, McCullough ML, Phillips KM, Swain JF, Champagne CM, Hoben KP, for the DASH Collaborative Research Group: Descriptive characteristics of the dietary patterns used in the Dietary Approaches to Stop Hypertension trial. J Am Diet Assoc 1999, 99(suppl):S19-S27.

20. Svetkey LP, Sacks FM, Obarzanek E, Vollmer WM, Appel LJ, PaoHwa L, Karanja NM, Harsha DW, Bray GA, Aickin M, Proschan MA, Windhauser MM, Swain JF, McCarron PB, Rhodes DG, Laws $\mathrm{RL}$, for the DASH-Sodium Collaborative Research Group. The DASH Diet, Sodium Intake and Blood Pressure Trial (DASHsodium): rationale and design. J Am Diet Assoc 1999, 99 (suppl):S96-S104.

21. Statement in response to NHLBI news release on DASHSodium Study [press release]. Washington, DC/Alexandria, VA: Salt Institute, May 172000

22. Raloff J: Salt trial provokes DASH of skepticism. Science News 2000, 157:340-341.

23. Svetkey LP, Simons-Morton D, Vollmer WM, Appel LJ, Conlin PR, Ryan $\mathrm{DH}$, Ard J, Kennedy BM: Effects of dietary patterns on blood pressure: subgroup analysis of the Dietary Approaches to Stop Hypertension (DASH) randomized clinical trial. Arch Intern Med 1999, 159:285-293.

24. MacGregor GA, Markandu ND, Sagnella GA, Singer DR, Cappuccio FP: Double-blind study of three sodium intakes and longterm effects of sodium restriction in essential hypertension. Lancet 1989, 2:1244-1247.

25. US Dept of Health and Human Services, Public Health Service, $\mathrm{NIH}, \mathrm{NHLBI}$ : Implementing recommendations for dietary salt reduction: Where are we? Where are we going? How do we get there? Bethesda: NIH/NHLBI Publication No. 55-728N. 